\title{
The Impact of Obesity on the Cardiovascular System
}

\author{
Imre Csige, ${ }^{1}$ Dóra Ujvárosy, ${ }^{1}$ Zoltán Szabó $\mathbb{D}^{1},{ }^{1}$ István Lórincz, ${ }^{1}$ György Paragh, ${ }^{2}$ \\ Mariann Harangi, ${ }^{2}$ and Sándor Somodi $\mathbb{D D}^{2,3}$ \\ ${ }^{1}$ Department of Emergency Medicine, Faculty of Medicine, University of Debrecen, Hungary \\ ${ }^{2}$ Division of Metabolism, Department of Internal Medicine, Faculty of Medicine, University of Debrecen, Hungary \\ ${ }^{3}$ Division of Clinical Pharmacology, Faculty of Pharmacy, University of Debrecen, Hungary
}

Correspondence should be addressed to Zoltán Szabó; szaboz.med@gmail.com

Imre Csige and Dóra Ujvárosy contributed equally to this work.

Received 12 July 2018; Revised 12 September 2018; Accepted 27 September 2018; Published 4 November 2018

Guest Editor: Gaetano Santulli

Copyright (c) 2018 Imre Csige et al. This is an open access article distributed under the Creative Commons Attribution License, which permits unrestricted use, distribution, and reproduction in any medium, provided the original work is properly cited.

Obesity is a growing health problem worldwide. It is associated with an increased cardiovascular risk on the one hand of obesity itself and on the other hand of associated medical conditions (hypertension, diabetes, insulin resistance, and sleep apnoea syndrome). Obesity has an important role in atherosclerosis and coronary artery disease. Obesity leads to structural and functional changes of the heart, which causes heart failure. The altered myocardial structure increases the risk of atrial fibrillation and sudden cardiac death. However, obesity also has a protective effect on the clinical outcome of underlying cardiovascular disease, the phenomenon called obesity paradox. The improved cardiac imaging techniques allow the early detection of altered structure and function of the heart in obese patients. In this review, we attempt to summarize the relationship between obesity and cardiovascular diseases and outline the underlying mechanisms. The demonstrated new techniques of cardiac diagnostic procedures allow for the early detection and treatment of subclinical medical conditions and, therefore, the prevention of cardiovascular events.

\section{Introduction}

Obesity has been a health problem of growing significance all over the world; its prevalence is increasing in both developed and developing countries [1]. According to WHO data, 39\% of the global population above 18 years of age are overweight and of these, $13 \%$ are obese. Numerous studies have demonstrated a relationship between obesity and cardiovascular diseases (stable coronary disease, acute myocardial infarction, heart failure, cardiac arrhythmias, and sudden cardiac death). The association between obesity and hypertension, diabetes mellitus, dyslipidaemias, and sleep apnoea syndrome has also been shown to increase the incidence of cardiovascular disorders [2].

Body mass index (BMI) is used for measuring the extent of obesity; however, it gives no information on fat distribution, which is of high significance in cardiovascular risk [3]. Therefore, novel clinical measurements (e.g., abdominal circumference and the calculation of waist/hip ratio) have been introduced with the aim of characterizing central or abdominal obesity. Abdominal circumference above $102 \mathrm{~cm}$ in the case of men and above $88 \mathrm{~cm}$ in the case of women qualifies as central obesity and involves increased cardiovascular risk [4]. A waist/hip ratio above 0.9 in the case of men and above 0.85 in the case of women indicates central obesity [5].

\section{The Relationship between Obesity and Atherosclerosis}

In the past three decades, many details of the pathophysiological processes of obesity and atherosclerosis have been revealed. Previously, both diseases had been regarded as lipid storage disorders with triglyceride accumulation in the fat tissue and cholesterol esters in atherosclerotic plaques. Nowadays, both obesity and atherosclerosis are considered chronic inflammatory conditions, in which the activation of 


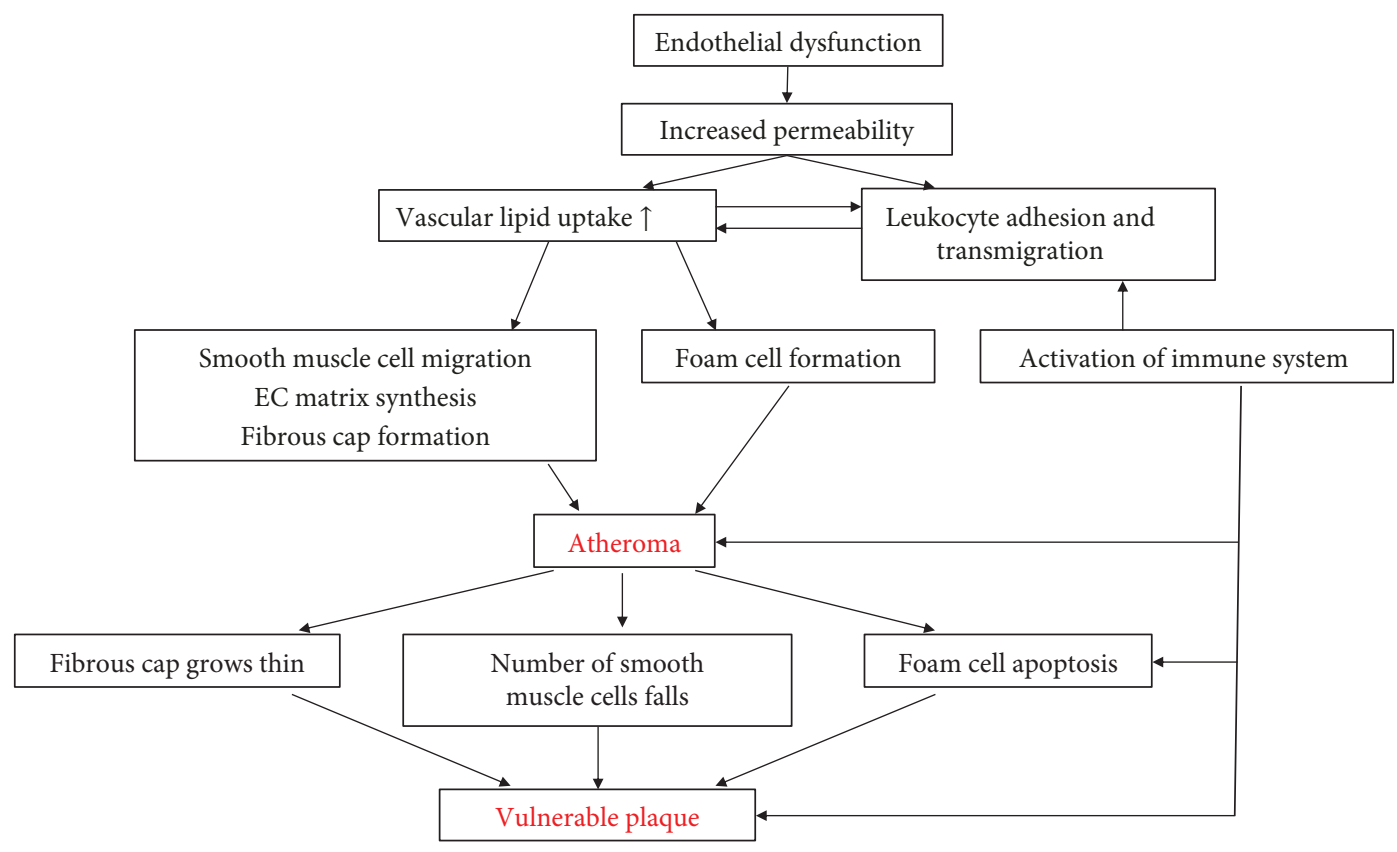

FIGURE 1: The pathomechanism of coronary artery disease in obesity.

both nonspecific and adaptive immune processes is assigned a significant role $[6,7]$.

The pathogenesis of obesity and atherosclerosis has several common factors. In both cases, lipids, oxidized LDL particles, and free fatty acids activate the inflammatory process and trigger the disease. Inflammation is responsible for all the steps towards atherosclerosis, from early endothelial dysfunction to the atherosclerotic plaques causing complications, and is related to obesity, insulin resistance, and type 2 diabetes. The fatty tissue releases adipocytokines, which induce insulin resistance, endothelial dysfunction, hypercoagulability, and systemic inflammation, thereby facilitating the atherosclerotic process. In visceral obesity, inflammatory adipocytokines (e.g., TNF- $\alpha$, IL-6, MCP-1, leptin, and resistin) rise to higher levels. Moreover, the increased level of C-reactive protein is associated with an increased risk of myocardial infarction, peripheral vascular disease, and diabetes mellitus [8-10]. Interestingly, a clinical study performed on obese women confirmed that body weight reduction achieved through lifestyle changes reduces the level of inflammatory biomarkers and insulin resistance. In the course of the process, adiponectin, an anti-inflammatory and insulinsensitizing adipocytokine, is released [11]. It is important to understand the relationship between the inflammatory process and atherosclerosis and the accelerating role of obesity.

\section{Obesity and Coronary Artery Disease}

Obesity is closely related to coronary atherosclerosis. A study performed on young patients showed that atherosclerosis begins several decades before manifested coronary artery disease. Atherosclerotic vascular lesions of patients with higher BMI values are more frequent and advanced compared to subjects with normal body weight [12]. According to longitudinal studies, at least two decades of obesity is likely to be an independent risk factor of coronary artery disease $[13,14]$. A $10 \mathrm{~kg}$ rise in body weight increases the risk of coronary artery disease by $12 \%$ and at the same time, systolic blood pressure rises by $3 \mathrm{mmHg}$ and diastolic by $2.3 \mathrm{mmHg}$ as a consequence [15] (Figure 1). Furthermore, in the case of non-ST segment elevation myocardial infarction (NSTEMI) affecting young people, excess weight can be considered the most important risk factor, ahead of smoking. The higher the BMI, the sooner NSTEMI develops [16]. The same relationship can also be observed in the case of ST elevation myocardial infarction (STEMI) [17]. Based on the data available, obesity is an independent risk factor of STEMI developing at a young age [18] but at the same time excess weight can also be related to other vascular events. An increase in BMI by one unit causes a $4 \%$ rise in the risk of ischemic and a 6\% rise in haemorrhagic strokes [19].

\section{Obesity and Heart Failure}

The frequency of heart failure is increasing; it is one of the major causes of death globally with a prevalence of approximately $3 \%$ in developed countries [20]. A close correlation can be observed between heart failure and obesity. According to data from the Framingham Heart Study, the rise of BMI by $1 \mathrm{~kg} / \mathrm{m}^{2}$ increases the risk of heart failure by $5 \%$ in the case of men and 7\% in the case of women [21]. Studies on heart failure show that $32 \%-49 \%$ of patients suffering from heart failure are obese and $31 \%-40 \%$ are overweight. In the case of obese and overweight patients, heart failure develops 10 years earlier than in the case of subjects with a normal BMI. The duration of morbid obesity is closely correlated to the development of heart failure: after 20 years of obesity, the prevalence of heart failure grows by $70 \%$ and after 30 years, the 


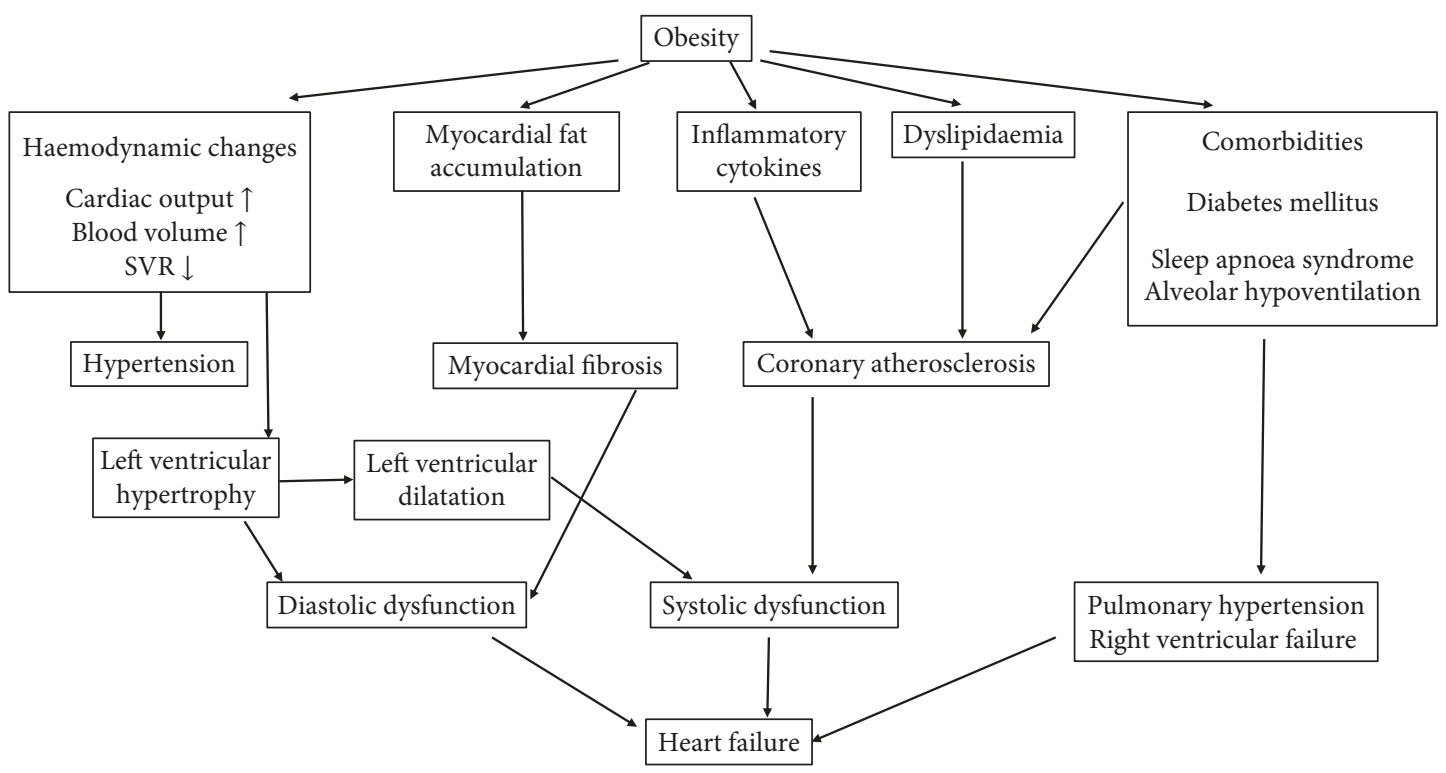

FIgURE 2: The pathomechanism of heart failure in obesity.

prevalence rises by $90 \%$ [22]. The significance of obesity is indicated by the fact that the Framingham Heart Study emphasized the pathogenic role of obesity for the development of heart failure in $11 \%$ of males and $14 \%$ of females [21]. The structural and functional changes of the heart observed in obesity alone contribute to a deterioration in myocardial function, which is often referred to as "obesity cardiomyopathy" [23].

Obesity leads to heart failure through several direct and indirect mechanisms. Excess weight leads to haemodynamic changes. A rise in both cardiac output and blood pressure has been observed; an increase in BMI of $5 \mathrm{~kg} / \mathrm{m}^{2}$ involved a $5 \mathrm{mmHg}$ rise in systolic blood pressure [24]. On one hand, it is related to the activation of the renin-angiotensinaldosterone system and on the other hand, to the increased activity of the sympathetic nervous system $[25,26]$. Obesity increases both the aldosterone level and the mineralocorticoid receptor expression, which promote interstitial cardiac fibrosis, platelet aggregation, and endothelial dysfunction. The above mechanisms explain the results of EMPHASISHF trial: eplerenone therapy was more beneficial for treatment of heart failure with reduced ejection fraction in patients with abdominal obesity [27, 28]. Increased blood volume facilitates venous backflow, which enhances ventricular preload causing increased ventricular wall tension and ultimately leading to ventricular dilatation. Abdominal obesity is associated with subclinical left ventricular dysfunction [29]. Hypertension increases left ventricular afterload, which raises the danger of structural and electrical myocardial remodelling. This process ultimately leads to left ventricular hypertrophy and to diastolic and later to systolic ventricular dysfunction [30].

Inflammatory cytokines (TNF- $\alpha$, IL-1, IL-6, IL-8, etc.), whose production is increased in obesity, also play an important role in the development of heart failure [31-33]. The inflammatory mediators and acute-phase proteins in circulation cause myocardial fibrosis, which increases myocardial stiffness and may thereby lead to diastolic and later to systolic heart failure [34]. Through their effect on metabolism, tissue structure, and the extracellular matrix, leptin and adiponectin contribute directly to the myocardial transformation. Triglyceride accumulation in the cardiac muscle can regularly be observed in obese patients and facilitates the generation of toxic metabolites (e.g., ceramide and diacylglycerol), thus enhancing the apoptosis of cardiomyocytes [35-37]. The integrity of skeletal muscle mass is crucial for retaining the physical activity. Diet-induced obesity has been shown to promote muscle atrophy and catabolism. This process plays an important role in the progression of CVD in obese patients [38].

Moreover, obesity has been shown to increase the chances of heart failure not only by itself but also through the associated medical comorbidities. The frequently appearing insulin resistance reduces the contractility of the myocardium [39], while it enhances the activity of the renin-angiotensin-aldosterone system, which can result in hypertrophy and apoptosis of cardiac myocytes and to myocardial fibrosis [40]. Alterations in lipid metabolism enhance atherosclerosis and thereby the risk of ischemic cardiomyopathy. Unsurprisingly, obesity is therefore an independent risk factor of coronary artery disease [41]. Myocardial lipid accumulation and enhanced fibrosis can also play a pathogenic role in the genesis of various cardiac arrhythmias, which may contribute to the development of heart failure [42, 43] (Figure 2).

\section{Obesity and Cardiac Arrhythmias}

Numerous studies have demonstrated the connection between obesity and the increased risk of cardiac arrhythmias and sudden cardiac death $[44,45]$. Hippocrates concluded in the 4th century already that "sudden death is more common in those who are naturally fat than in the lean." 


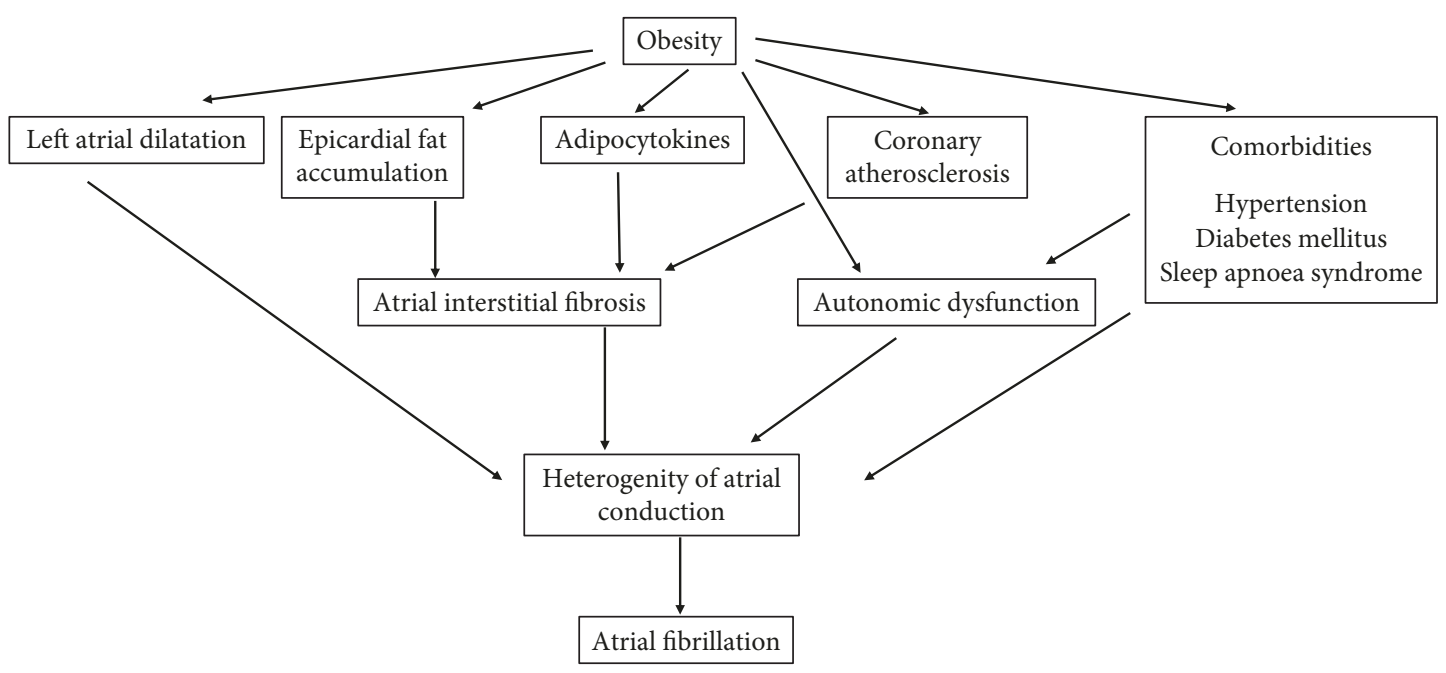

FIGURE 3: The pathomechanism of atrial fibrillation in obesity.

5.1. Obesity and Atrial Fibrillation. Among the cardiac arrhythmias, atrial fibrillation has the highest clinical significance. Its incidence and prevalence is increasing worldwide, affecting $1-2 \%$ of the adult population. Atrial fibrillation is responsible for about one third of the hospitalizations due to arrhythmias; it significantly increases morbidity, mortality, and health care expenditure. Over 6 million Europeans suffer from this type of arrhythmia, and this number is estimated to double in the next fifty years [46]. The occurrence of atrial fibrillation shows a correlation with age; its frequency among people aged $40-50$ is under $0.5 \%$, while it rises to $5-10 \%$ by the age of 80 years. Various studies have proven the relationship between obesity and atrial fibrillation. Obese patients have a 1.52 times higher risk for the development of atrial fibrillation compared to the normal weight population $[45,47,48]$. A 1-unit rise in BMI increases the frequency of newly developed atrial fibrillation by $4 \%$. At the same time, in patients with atrial fibrillation, there is an increased risk for sudden cardiac death, stroke, thromboembolic complications, and heart failure. Moreover, atrial fibrillation lengthens hospitalization and worsens quality of life and physical capacity [46].

5.2. Structural and Electrical Remodelling Caused by Obesity. Obesity causes numerous anatomical and functional changes which play an important role in arrhythmogenesis. Left atrial dilation and dysfunction are known consequences of obesity. A $5 \mathrm{~mm}$ increase in left atrial cross diameter has been shown to raise the chances of paroxysmal atrial fibrillation 1.39 times [49]. Furthermore, recent studies have confirmed the correlation between increased epicardial fat tissue and atrial fibrillation. Through its paracrine effect, epicardial fat contributes to the development of atrial interstitial fibrosis. The increased epicardial fat, the infiltration of myocardium with adipocytes, and fibrosis together result in a heterogeneous atrial pulse conduction, e.g., anisotropy, which contributes to endo- and epicardial electrical dissociation [50-52]. All these processes facilitate the development of atrial reentry, which serves as the electrophysiological background of atrial fibrillation. Tests on both animals and humans have proven that the expansion of fatty tissue is strongly associated with insufficient capillarisation, thus myocardial hypoxia. Increased adipocyte necrosis triggers macrophage, neutrophil, and lymphocyte infiltration as well as the accumulation of proinflammatory cytokines [53] (Figure 3). It has also been proven that atrial fibrillation in obese patients shortens the refractory period of the atrial and pulmonary vein myocardial cells [54]. Enhanced adiposity triggers alterations in the ECG, too: higher amplitude $P$ waves with lengthened duration, longer PR time, and $P$ wave terminal force [55]. Animal research findings reveal that diet-induced obesity may be associated with prolonged atrial conduction time and heterogeneous pulse conduction. The same electrical changes were observed in the case of atrial interstitial fibrosis, increased inflammatory activity, and myocardial lipid accumulation. Remarkably, similar changes were registered in cases of congestive heart failure, hypertension, and myocardial infarction. However, the pathogenic role of complex signalisation pathways (TGF, cTGF, and endothelial system) in atrial fibrosis is not yet precisely elucidated [56].

5.3. The Role of Obesity and Low-Grade Inflammation in Arrhythmogenesis. The reason underlying atrial fibrillation is assumed to be the low-grade inflammation, which is mainly observed in relation to obesity. In obese patients, an increased number of leukocytes and a heightened presence of various inflammatory cytokines (C-reactive protein, interleukin-6, and tumor necrosis factor- $\alpha$ ) were detected. TNF- $\alpha$ may increase the local arrhythmic vulnerability of the pulmonary vein, thereby causing atrial fibrillation $[57,58]$. TGF- $\beta$ plays an important role in the development of myocardial fibrosis [59] (Figure 3). The leptin released from adipocytes lengthens the duration of the action potential and thereby may have an arrhythmogenic effect. The roles of low-grade inflammation and oxidative stress in arrhythmogenesis have not been clearly identified yet. All the above observations 
are associative, so the association through inflammation remains a hypothesis only. Modifications of the ion channel function and calcium homeostasis disorder are also assumed to be underlying phenomena [60].

5.4. Further Arrhythmogenic Factors Associated with Obesity. In the case of atrial fibrillation, the level of atrial natriuretic peptide significantly rises and shows correlation with expected mortality [61]. Additionally, in patients suffering from atrial fibrillation, the activation of the renin-angiotensin system may be associated with atrial fibrosis and electrical remodelling [62]. Furthermore, obesity may cause autonomous nervous system dysfunction. In the case of overweight patients, excessive sympathetic activity and decreased vagal tone and consequently increased urine norepinephrine secretion and cardiac rhythm disturbances were detected [63].

\section{Obesity and Sudden Cardiac Death}

Various studies indicate a relationship between sudden cardiac death and obesity [64]. Obesity is considered an independent risk factor in the development of ventricular tachyarrhythmias. The structural remodelling in the ventricular myocardium of obese patients results in left ventricular hypertrophy and consequential systolic and diastolic ventricular dysfunctions. Myocardial hypertrophy, fibrosis, focal myocardial disarray, and increased volume of epicardial fat are also parts of the pathological process [65].

Obesity may also be associated with prolonged and inhomogeneous ventricular repolarization, which can manifest in the prolongation of the QT interval and QT interval corrected to the heart rate (QTc) measured on the 12-lead surface electrocardiogram. These ECG parameters are known as independent markers of cardiovascular mortality, and their pathological prolongation may draw attention to an increased risk of ventricular arrhythmias [66]. In the development of the pathologically prolonged and inhomogeneous repolarization observed in obesity and the electrical instability involved as a consequence, the main roles are assigned to obesity cardiomyopathy, the altered function of voltage-dependent potassium channels, and autonomic dysregulation $[67,68]$.

\section{The Obesity Paradox}

Even though obesity involves enhanced risk for the development of cardiovascular abnormalities, in the case of an already developed disease, excess weight and obesity are associated with a favorable prognosis. The phenomenon known as obesity paradox has been observed in the case of several cardiovascular diseases including acute and chronic heart failures $[69,70]$, coronary artery disease [71], acute myocardial infarction [72], hypertension, and atrial fibrillation $[73,74]$.

7.1. The Obesity Paradox and Heart Failure. In the case of patients suffering from heart failure, the findings of numerous meta-analyses have proven the phenomenon of the obesity paradox.
According to a meta-analysis processing observational studies and summarizing the data of 28,209 patients altogether, during a follow-up time of 2.7 years on the average, in the case of overweight persons with heart failure, overall mortality was $16 \%$ lower and cardiovascular mortality was $19 \%$ lower compared to the control group. The above data are even more favorable in the case of obese patients with heart failure: overall mortality rate was 33\% lower and cardiovascular mortality was $40 \%$ lower compared to normal weight patients [70].

According to a more recent meta-analysis processing the data of 22,807 patients, during an average follow-up time of 2.85 years, the relative risk of overall death in the case of overweight patients with heart failure was 0.78 (confidence interval 0.68-0.89), the relative risk of cardiovascular death was 0.79 (confidence interval 0.7-0.9), and that of hospitalization was 0.92 (confidence interval 0.86-0.97) compared to normal weight patients with heart failure. At the same time, no favorable changes were observed in the case of obese patients either in cardiovascular mortality or in hospitalization; only the risk of overall mortality was lower compared to normal weight patients [75].

The analysis of Heart Failure Registry of the Heart Failure Association of the European Society of Cardiology showed inverse relationship between all-cause and cardiovascular mortality and body surface area (BSA) levels. Hospitalizations due to heart failure were not associated with BSA [76].

7.2. The Obesity Paradox and Coronary Revascularisation. The correlation between BMI and the outcome of clinical revascularisation was first reported in 1996, in the case of patients who had been administered balloon coronary angioplasty. According to the hospital findings, the mortality rate was higher in the case of normal weight and obese patients than in that of overweight patients [77].

Data of the multicentre BARI register processing the data of 3634 patients administered coronary revascularisation (primary coronary intervention (PCI) with catheter or surgical coronary revascularisation $(\mathrm{CABG})$ ) reveal that in the acute hospitalization period, there was an inverse relationship between complications and BMI only in the case of PCI-treated patients. Remarkably, in the case of the CABG group, there was an inverse relationship between mortality and BMI only 5 years after the operation [78]. It must be emphasized that clinical events following surgery, like arterial hypotension, pulmonary oedema, the deterioration of kidney function, bleeding, and mortality, were more frequent in the case of thin than in that of overweight or obese patients.

According to data of the Scottish Coronary Revascularisation Register, in the case of patients who had not suffered from coronary artery disease before and who underwent elective PCI intervention, lower mortality rate was observable in the next 5 years if their BMI value was between 27 and $30 \mathrm{~kg} / \mathrm{m}^{2}$ [79].

According to data of the APPROACH register, mortality following PCI and CABG was more favorable in the case of overweight or obese persons compared to those with normal body weight [80]. 
On the contrary, other studies on coronary stent implantation did not support the phenomenon of the "obesity paradox."

Interestingly, in the course of using traditional bare metal stents (BMS), an inverse relationship could be observed between BMI and clinical outcome. In the case of BMS implantation, obesity was an independent predictor of instent restenosis. However, a relationship between obesity and adverse events was, surprisingly, not confirmed after drug-eluting stent (DES) implantation [81].

At the same time, it is still disputed if obese coronary artery disease patients would benefit from DES implantation. According to data from the German DES.DE register, the rate of hospital complications did not differ in the cases of normal weight, overweight, or obese patients. At the time of the one-year follow-up, there was similarly no difference in mortality, myocardial infarction, target vessel revascularisation, or bleeding complications [82].

7.3. Explanation for the Obesity Paradox. It is well known that excess weight and obesity, as phenomena of the metabolic syndrome, lead to enhanced cardiovascular risk, endothelial dysfunction, inflammation, and atherosclerosis. The most important question is what can the explanation be for the better prognosis established in the case of overweight and obese cardiovascular patients compared to normal weight patients.

The analyses show that in the case of $2 \%$ of thin patients, comorbid conditions, mostly malignant diseases, heart failure, malnutrition, or multiple organ dysfunction, can be observed. Moreover, these patients were much older than their normal weight or obese counterparts [78, 83]. Obviously, in the case of older age patients in a generally weak condition, clinical outcomes after coronary events proved to be worse irrespective of the success of the reperfusion [84]. Advanced age and comorbid factors often result in loss of body weight [85]. In obesity, the increased level of serum lipoproteins may neutralize bacterial toxins and circulating cytokines [86]. The low level of adiponectin and the reduced catecholamine response, too, may increase the chances of survival [87]. Furthermore, in the case of obese patients, cardiovascular diseases are usually diagnosed and treated earlier than in the case of thin patients [88]. In the case of overweight and obese patients, the dose of medication required in treating the cardiovascular disease is easier to titrate considering the associated hypertension and obese patients are also more compliant with regimen than their normal weight counterparts. A possible explanation of obesity paradox is that in critical ill patients, fat which mobilized from excess adipose tissue provides energy and prevents lean tissue wasting more efficiently than exogenous nutrients [89]. In heart failure, a metabolic cardiac remodeling occurs, the fatty acid oxidation is impaired, and the glucose uptake and glycolysis are increased. The metabolic imbalance between higher energetic demand and substrate availability and lower oxidative capacity and cofactor availability (carnitine and CoA) leads to the accumulation of intermediates, which impair cardiac function, and substrates are diverged towards lipotoxic signaling pathways [90]. Alterations in mitochondrial dynamics, respiratory capacity, and ATP synthesis play an important role in the chronic cardiac energy deficit observed in heart failure [91]. Improved fatty acid utilization via dietary modification significantly ameliorates mitochondrial fragmentation and cardiac dysfunction [92].

According to more recent theories explaining the "obesity paradox," obese patients have "larger blood vessels" and in the course of PCI, worse results are obtained in the case of patients with narrowed blood vessels [93, 94].

Antithrombotic medication is usually administered in standard doses rather than adjusted to body weight, so the dose may be too high for normal weight and thin patients, which may result in bleeding complications and this, in turn, may also contribute to higher mortality [95].

If the outcomes of cardiopulmonary stress tests are also considered, the favorable effect of higher BMI was shown to disappear [96]. According to other views, the greater muscle strength associated with a higher BMI has a favorable effect on so-called "cardiorespiratory fitness" $[97,98]$. Peak oxygen consumption $\left(\mathrm{VO}_{2}\right)$ is a positive predictor of longer survival among patients with heart failure. In multivariate analysis using $\mathrm{VO}_{2}$, the protective role of BMI for survival disappears [99]. The survival paradox of BMI disappears also in diabetic patients with heart failure [100]. These results support the superior prognostic power of peak oxygen consumption and diabetes compared to obesity, which attenuates the "obesity paradox" phenomenon [101].

According to the endotoxin-lipoprotein hypothesis, obese patients have higher cholesterol and lipoprotein levels, which reduce the concentration of inflammatory agents and may thus have anti-inflammatory and probably also arrhythmia protective effect. The observation that the myocardial accumulation of fat enhances the density of TNF- $\alpha$ I and II receptors, thereby facilitating the development of an antiarrhythmogenic environment, may at the same time probably serve as a kind of explanation for the development of the obesity paradox $[57,58]$.

\section{Cardiac Consequences of the Haemodynamic Changes Triggered by Obesity}

The volume stress associated with obesity causes both structural and functional changes in the heart. The most frequent structural changes are left ventricular hypertrophy (LVH) and left ventricular dilation, and as a consequence, diastolic, then systolic dysfunction, epicardial fat accumulation, and left atrial enlargement occur. The circulating blood volume rises; the increased cardiac output is provided mainly by the increased stroke volume and, to a lesser extent, by the increased cardiac frequency as an effect of the enhanced sympathetic tone. The above mechanisms often cause hypertension [23] (Figure 2).

\section{Cardiology Diagnostics in Obesity}

Considering the enhanced cardiovascular risk and inclination to arrhythmia observed in obesity, cardiology diagnostics are important even in the case of symptomfree obese patients. The routine 12-lead surface ECG and 


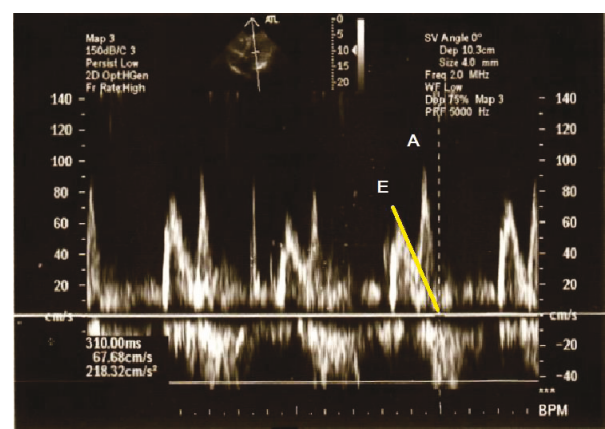

FIGURE 4: Diagnosing diastolic dysfunction with echocardiography. Transmitral flow velocities measured with pulsatile wave Doppler technique. The ratio $(E / A)$ of the early diastolic peak velocity $(E)$ and the late diastolic velocity $(A)$ is lower than 1 . Deceleration time (DT) is the interval from the peak of the wave $E$ to its end (marked with a yellow line). In this case, its prolongation was measured $(310 \mathrm{sec})$. The above alterations prove the left ventricular diastolic dysfunction (relaxation disorder).

echocardiography are available at almost any cardiology outpatient unit nowadays.

9.1. Echocardiography. According to a meta-analysis published in 2014, the frequency of left ventricular hypertrophy $(\mathrm{LVH})$ in obese patients is 56\%; the risk of the development of LVH in the case of obese patients is 4.19 times higher than in the case of people with normal weight. Excentric hypertrophy is more frequent than the concentric type $(66 \%$ vs. $34 \%, p<0.001)$ [102]. LVH is usually calculated by the left ventricular mass index (LVMI), whereby it is indexed to height ${ }^{2.7}$. This shows a good correlation with cardiovascular mortality. Less frequently, indexation to body surface area is used [103].

In obesity, the prevalence of diastolic dysfunction is above $50 \%$ and shows close correlation with abdominal circumference. Among cardiovascular risk factors, age, sex, and hypertension increase the likelihood of diastolic dysfunction, which is demonstrated by what is referred to as the E/A ratio: the ratio of the mitral flow velocities measured in the early diastole $(E)$ and late diastole $(A)$. The value of the ratio is less than 1 in the case of diastolic dysfunction, primarily due to a rise in the peak velocity of $A$. The diagnosis also requires establishing the so-called deceleration time, i.e., the time taken from the peak to the end of the $A$ wave, while the velocities of the mitral annular longitudinal movement obtained by the tissue Doppler imaging technique constitute further complementary and specification data (Figure 4). Left atrial volume enlargement is also often associated with diastolic dysfunction and can thus be considered as a marker of the latter [104]. At the same time, conventional echocardiography is sometimes unsuitable for the early diagnosis of systolic or diastolic dysfunction as the measurable parameters may still be in the normal range.

In the past decade, new echocardiographic techniques have become available that make a yet earlier diagnosis of systolic and diastolic dysfunctions possible [105]. Color Doppler imaging detects the movement and deformity of the myocardium and is thereby able to show changes in contractility [106]. The so-called "integrated backscatter" technique is able to sense changes in the reflectivity and weakening of the myocardium. These are primarily determined by the myocardial collagen content and are also influenced by the size and microstructure of cardiac muscle cells. The technique primarily provides information on myocardial stiffness, contractility, and the extent of fibrosis, in a noninvasive way $[107,108]$. Pulsatile wave tissue Doppler imaging (PW-TDI) measures the cardiac muscle movement velocity. These Doppler parameters are more precise and easier to reproduce than those obtained by means of 2D, M-mode echocardiography [109]. 3D imaging has lately been introduced in cardiology as well, which makes the determination of the ejection fraction (EF) and the volume of the left atrium and the left ventricle more precise [110]. A comparison with MRI imaging proved the advantages of $3 \mathrm{D}$ echocardiography.

9.2. Electrocardiography. In case of obesity, the QT interval corrected to the heart rate (QTc) is prolonged and QT dispersion (QTd) also increases [111, 112]. These electrocardiographic differences show a correlation with an enhanced disposition to ventricular arrhythmia. In the past two decades, new markers of ventricular repolarization have been identified, which characterize cardiac muscle vulnerability in coronary artery disease, hypertrophic cardiomyopathy, and long QT syndrome very well: T peak-end (Tpe) interval, T peak-end dispersion, and Tpe/QT ratio (arrhythmogenic index) [113-115]. Studies performed on obese patients showed, however, that statistically significant prolongation compared to the control values was observed only in the case of QT interval and QTc; there were no similar differences observed in the case of the other electrocardiographic parameters [116].

Using the above testing procedures, the slight structural, electrical, and functional changes of the heart can be detected. Consequently, symptom-free patients with enhanced risk for ventricular arrhythmias can be identified at an early stage.

\section{Summary}

Excess weight and obesity are associated with an increased risk of cardiovascular diseases. This is a consequence on the one hand of obesity itself and on the other hand of associated medical conditions (hypertension, diabetes, insulin resistance, and sleep apnoea syndrome). In case of already established cardiovascular diseases, the mortality of overweight and obese patients is often lower than that of people with a normal body weight, which is known as "obesity paradox." The exact mechanism of the latter is not clear yet. Considering the increased cardiovascular risk, the regular cardiology screening, and control of still symptom-free obese patients is important for the early diagnosis and treatment of subclinical medical conditions. 


\section{Conflicts of Interest}

The authors declare that they have no conflicts of interest.

\section{Acknowledgments}

This research was carried out with support from the GINOP2.3.2-15-2016-00005 fund.

\section{References}

[1] M. Ng, T. Fleming, M. Robinson et al., "Global, regional, and national prevalence of overweight and obesity in children and adults during 1980-2013: a systematic analysis for the Global Burden of Disease Study 2013," The Lancet, vol. 384, no. 9945, pp. 766-781, 2014.

[2] P. Poirier, T. D. Giles, G. A. Bray et al., "Obesity and cardiovascular disease: pathophysiology, evaluation, and effect of weight loss: an update of the 1997 American Heart Association Scientific Statement on Obesity and Heart Disease from the Obesity Committee of the Council on Nutrition, Physical Activity, and Metabolism," Circulation, vol. 113, no. 6, pp. 898-918, 2006.

[3] M. Zeller, P. G. Steg, J. Ravisy et al., "Relation between body mass index, waist circumference, and death after acute myocardial infarction," Circulation, vol. 118, no. 5, pp. 482-490, 2008.

[4] S. Yusuf, S. Hawken, S. Ôunpuu et al., "Effect of potentially modifiable risk factors associated with myocardial infarction in 52 countries (the INTERHEART study): case-control study," The Lancet, vol. 364, no. 9438, pp. 937-952, 2004.

[5] M. Ashwell and S. D. Hsieh, "Six reasons why the waistto-height ratio is a rapid and effective global indicator for health risks of obesity and how its use could simplify the international public health message on obesity," International Journal of Food Sciences and Nutrition, vol. 56, no. 5, pp. 303-307, 2005.

[6] V. Z. Rocha and P. Libby, "Obesity, inflammation, and atherosclerosis," Nature Reviews Cardiology, vol. 6, no. 6, pp. 399-409, 2009.

[7] R. Ross, "Atherosclerosis-an inflammatory disease," The New England Journal of Medicine, vol. 340, no. 2, pp. 115-126, 1999.

[8] S. E. Shoelson, L. Herrero, and A. Naaz, "Obesity, inflammation, and insulin resistance," Gastroenterology, vol. 132, no. 6, pp. 2169-2180, 2007.

[9] P. M. Ridker, "C-reactive protein and the prediction of cardiovascular events among those at intermediate risk: moving an inflammatory hypothesis toward consensus," Journal of the American College of Cardiology, vol. 49, no. 21, pp. 2129-2138, 2007.

[10] A. D. Pradhan, J. E. Manson, N. Rifai, J. E. Buring, and P. M. Ridker, "C-reactive protein, interleukin 6, and risk of developing type 2 diabetes mellitus," Journal of the American Medical Association, vol. 286, no. 3, pp. 327-334, 2001.

[11] K. Esposito, A. Pontillo, C. di Palo et al., "Effect of weight loss and lifestyle changes on vascular inflammatory markers in obese women: a randomized trial," JAMA, vol. 289, no. 14, pp. 1799-1804, 2003.

[12] H. C. McGill, C. A. McMahan, E. E. Herderick et al., "Obesity accelerates the progression of coronary atherosclerosis in young men," Circulation, vol. 105, no. 23, pp. 2712-2718, 2002.

[13] J. A. E. Manson, G. A. Colditz, M. J. Stampfer et al., “A prospective study of obesity and risk of coronary heart disease in women," New England Journal of Medicine, vol. 322, no. 13 , pp. $882-889,1990$.

[14] P. W. F. Wilson, R. B. D'Agostino, L. Sullivan, H. Parise, and W. B. Kannel, "Overweight and obesity as determinants of cardiovascular risk: the Framingham experience," Archives of Internal Medicine, vol. 162, no. 16, pp. 1867-1872, 2002.

[15] R. Din-Dzietham, Y. Liu, M. V. Bielo, and F. Shamsa, "High blood pressure trends in children and adolescents in national surveys, 1963 to 2002," Circulation, vol. 116, no. 13, pp. 1488-1496, 2007.

[16] M. C. Madala, B. A. Franklin, A. Y. Chen et al., "Obesity and age of first non-ST-segment elevation myocardial infarction," Journal of the American College of Cardiology, vol. 52, no. 12, pp. 979-985, 2008.

[17] S. R. Das, K. P. Alexander, A. Y. Chen et al., "Impact of body weight and extreme obesity on the presentation, treatment, and in-hospital outcomes of 50,149 patients with STsegment elevation myocardial infarction results from the NCDR (National Cardiovascular Data Registry)," Journal of the American College of Cardiology, vol. 58, no. 25, pp. 2642-2650, 2011.

[18] G. Jamil, M. Jamil, H. Alkhazraji et al., "Risk factor assessment of young patients with acute myocardial infarction," American Journal of Cardiovascular Disease, vol. 3, no. 3, pp. 170-174, 2013.

[19] C. J. Lavie, R. V. Milani, and H. O. Ventura, "Obesity and cardiovascular disease: risk factor, paradox, and impact of weight loss," Journal of the American College of Cardiology, vol. 53, no. 21, pp. 1925-1932, 2009.

[20] D. Mozaffarian, E. J. Benjamin, A. S. Go et al., "Heart disease and stroke statistics-2015 update: a report from the American Heart Association," Circulation, vol. 131, no. 4, pp. e29-322, 2015.

[21] S. Kenchaiah, J. C. Evans, D. Levy et al., "Obesity and the risk of heart failure," New England Journal of Medicine, vol. 347, no. 5, pp. 305-313, 2002.

[22] M. A. Alpert, B. E. Terry, M. Mulekar et al., "Cardiac morphology and left ventricular function in normotensive morbidly obese patients with and without congestive heart failure, and effect of weight loss," The American Journal of Cardiology, vol. 80, no. 6, pp. 736-740, 1997.

[23] M. A. Alpert, J. Omran, and B. P. Bostick, "Effects of obesity on cardiovascular hemodynamics, cardiac morphology, and ventricular function," Current Obesity Reports, vol. 5, no. 4, pp. 424-434, 2016.

[24] R. E. Schmieder and F. H. Messerli, "Does obesity influence early target organ damage in hypertensive patients?," Circulation, vol. 87, no. 5, pp. 1482-1488, 1993.

[25] I. A. Ebong, D. C. Goff Jr., C. J. Rodriguez, H. Chen, and A. G. Bertoni, "Mechanisms of heart failure in obesity," Obesity Research \& Clinical Practice, vol. 8, no. 6, pp. e540-e548, 2014.

[26] F. Rabbia, B. Silke, A. Conterno et al., "Assessment of cardiac autonomic modulation during adolescent obesity," Obesity Research, vol. 11, no. 4, pp. 541-548, 2003.

[27] A. Ahmed, M. R. Blackman, M. White, and S. D. Anker, "Emphasis on abdominal obesity as a modifier of eplerenone 
effect in heart failure: hypothesis-generating signals from EMPHASIS-HF," European Journal of Heart Failure, vol. 19, no. 9, pp. 1198-1200, 2017.

[28] A. Olivier, B. Pitt, N. Girerd et al., "Effect of eplerenone in patients with heart failure and reduced ejection fraction: potential effect modification by abdominal obesity. Insight from the EMPHASIS-HF trial," European Journal of Heart Failure, vol. 19, no. 9, pp. 1186-1197, 2017.

[29] C. Russo, F. Sera, Z. Jin et al., "Abdominal adiposity, general obesity, and subclinical systolic dysfunction in the elderly: a population-based cohort study," European Journal of Heart Failure, vol. 18, no. 5, pp. 537-544, 2016.

[30] G. de Simone, V. Palmieri, J. N. Bella et al., "Association of left ventricular hypertrophy with metabolic risk factors: the HyperGEN study," Journal of Hypertension, vol. 20, no. 2, pp. 323-331, 2002.

[31] B. Levine, J. Kalman, L. Mayer, H. M. Fillit, and M. Packer, "Elevated circulating levels of tumor necrosis factor in severe chronic heart failure," The New England Journal of Medicine, vol. 323, no. 4, pp. 236-241, 1990.

[32] G. Torre-Amione, S. Kapadia, C. Benedict, H. Oral, J. B. Young, and D. L. Mann, "Proinflammatory cytokine levels in patients with depressed left ventricular ejection fraction: a report from the studies of left ventricular dysfunction (SOLVD)," Journal of the American College of Cardiology, vol. 27, no. 5, pp. 1201-1206, 1996.

[33] T. Tsutamoto, T. Hisanaga, A. Wada et al., "Interleukin-6 spillover in the peripheral circulation increases with the severity of heart failure, and the high plasma level of interleukin-6 is an important prognostic predictor in patients with congestive heart failure," Journal of the American College of Cardiology, vol. 31, no. 2, pp. 391-398, 1998.

[34] M. Cavalera, J. H. Wang, and N. G. Frangogiannis, "Obesity, metabolic dysfunction, and cardiac fibrosis: pathophysiological pathways, molecular mechanisms, and therapeutic opportunities," Translational Research, vol. 164, no. 4, pp. 323-335, 2014.

[35] M. Karmazyn, D. M. Purdham, V. Rajapurohitam, and A. Zeidan, "Signalling mechanisms underlying the metabolic and other effects of adipokines on the heart," Cardiovascular Research, vol. 79, no. 2, pp. 279-286, 2008.

[36] K. Schram and G. Sweeney, "Implications of myocardial matrix remodeling by adipokines in obesity-related heart failure," Trends in Cardiovascular Medicine, vol. 18, no. 6, pp. 199-205, 2008.

[37] C. C. T. Smith and D. M. Yellon, "Adipocytokines, cardiovascular pathophysiology and myocardial protection," Pharmacology \& Therapeutics, vol. 129, no. 2, pp. 206-219, 2011.

[38] C. Lipina and H. S. Hundal, "Lipid modulation of skeletal muscle mass and function," Journal of Cachexia, Sarcopenia and Muscle, vol. 8, no. 2, pp. 190-201, 2017.

[39] T. B. Horwich and G. C. Fonarow, "Glucose, obesity, metabolic syndrome, and diabetes relevance to incidence of heart failure," Journal of the American College of Cardiology, vol. 55, no. 4, pp. 283-293, 2010.

[40] D. Cozzolino, A. Grandone, A. Cittadini et al., "Subclinical myocardial dysfunction and cardiac autonomic dysregulation are closely associated in obese children and adolescents: the potential role of insulin resistance," PLoS One, vol. 10, no. 4, article e0123916, 2015.
[41] P. Poirier, T. D. Giles, G. A. Bray et al., "Obesity and cardiovascular disease: pathophysiology, evaluation, and effect of weight loss," Arteriosclerosis, Thrombosis, and Vascular Biology, vol. 26, no. 5, pp. 968-976, 2006.

[42] B. A. Schoonderwoerd, M. D. Smit, L. Pen, and I. C. Van Gelder, "New risk factors for atrial fibrillation: causes of 'not-so-lone atrial fibrillation'," Europace, vol. 10, no. 6, pp. 668-673, 2008.

[43] O. Asghar, U. Alam, S. A. Hayat, R. Aghamohammadzadeh, A. M. Heagerty, and R. A. Malik, "Obesity, diabetes and atrial fibrillation; epidemiology, mechanisms and interventions," Current Cardiology Reviews, vol. 8, no. 4, pp. 253264, 2012.

[44] H. B. Hubert, M. Feinleib, P. M. McNamara, and W. P. Castelli, "Obesity as an independent risk factor for cardiovascular-disease: a 26-year follow-up of participants in the Framingham Heart Study," Circulation, vol. 67, no. 5, pp. 968-977, 1983.

[45] T. J. Wang, H. Parise, D. Levy et al., "Obesity and the risk of new-onset atrial fibrillation,” JAMA, vol. 292, no. 20, pp. 2471-2477, 2004.

[46] Authors/Task Force Members, A. J. Camm, G. Y. H. Lip et al., "2012 focused update of the ESC guidelines for the management of atrial fibrillation: an update of the 2010 ESC guidelines for the management of atrial fibrillation: developed with the special contribution of the European Heart Rhythm Association," Ep Europace, vol. 14, no. 10, pp. 1385-1413, 2012.

[47] U. B. Tedrow, D. Conen, P. M. Ridker et al., "The long- and short-term impact of elevated body mass index on the risk of new atrial fibrillation: the WHS (women's health study)," Journal of the American College of Cardiology, vol. 55, no. 21, pp. 2319-2327, 2010.

[48] A. S. Gami, D. O. Hodge, R. M. Herges et al., "Obstructive sleep apnea, obesity, and the risk of incident atrial fibrillation," Journal of the American College of Cardiology, vol. 49, no. 5, pp. 565-571, 2007.

[49] G. Di Salvo, G. Pacileo, E. M. Del Giudice et al., "Atrial myocardial deformation properties in obese nonhypertensive children," Journal of the American Society of Echocardiography, vol. 21, no. 2, pp. 151-156, 2008.

[50] S. Zlochiver, V. Munoz, K. L. Vikstrom, S. M. Taffet, O. Berenfeld, and J. Jalife, "Electrotonic myofibroblast-tomyocyte coupling increases propensity to reentrant arrhythmias in two-dimensional cardiac monolayers," Biophysical Journal, vol. 95, no. 9, pp. 4469-4480, 2008.

[51] B. Maesen, S. Zeemering, C. Afonso et al., "Rearrangement of atrial bundle architecture and consequent changes in anisotropy of conduction constitute the 3-dimensional substrate for atrial fibrillation," Circulation: Arrhythmia and Electrophysiology, vol. 6, no. 5, pp. 967-975, 2013.

[52] J. Eckstein, S. Zeemering, D. Linz et al., "Transmural conduction is the predominant mechanism of breakthrough during atrial fibrillation: evidence from simultaneous endo-epicardial high-density activation mapping," Circulation: Arrhythmia and Electrophysiology, vol. 6, no. 2, pp. 334-341, 2013.

[53] M. Pasarica, O. R. Sereda, L. M. Redman et al., "Reduced adipose tissue oxygenation in human obesity: evidence for rarefaction, macrophage chemotaxis, and inflammation without an angiogenic response," Diabetes, vol. 58, no. 3, pp. 718-725, 2009. 
[54] T. M. Munger, Y. X. Dong, M. Masaki et al., "Electrophysiological and hemodynamic characteristics associated with obesity in patients with atrial fibrillation," Journal of the American College of Cardiology, vol. 60, no. 9, pp. 851-860, 2012.

[55] J. W. Magnani, F. L. Lopez, E. Z. Soliman, R. F. Maclehose, R. S. Crow, and A. Alonso, "P wave indices, obesity, and the metabolic syndrome: the atherosclerosis risk in communities study," Obesity, vol. 20, no. 3, pp. 666-672, 2012.

[56] H. S. Abed, C. S. Samuel, D. H. Lau et al., "Obesity results in progressive atrial structural and electrical remodeling: implications for atrial fibrillation," Heart Rhythm, vol. 10, no. 1, pp. 90-100, 2013.

[57] S. H. Lee, Y. C. Chen, Y. J. Chen et al., "Tumor necrosis factor- $\alpha$ alters calcium handling and increases arrhythmogenesis of pulmonary vein cardiomyocytes," Life Sciences, vol. 80, no. 19, pp. 1806-1815, 2007.

[58] V. Mohamed-Ali, S. Goodrick, K. Bulmer, J. M. P. Holly, J. S. Yudkin, and S. W. Coppack, "Production of soluble tumor necrosis factor receptors by human subcutaneous adipose tissue in vivo," American Journal of Physiology-Endocrinology and Metabolism, vol. 277, no. 6, pp. E971-E975, 1999.

[59] N. Venteclef, V. Guglielmi, E. Balse et al., "Human epicardial adipose tissue induces fibrosis of the atrial myocardium through the secretion of adipo-fibrokines," European Heart Journal, vol. 36, no. 13, pp. 795-805, 2015.

[60] E. M. Jeong, M. Liu, M. Sturdy et al., "Metabolic stress, reactive oxygen species, and arrhythmia," Journal of Molecular and Cellular Cardiology, vol. 52, no. 2, pp. 454-463, 2012.

[61] A. Rossi, M. Enriquez-Sarano, J. C. Burnett Jr., A. Lerman, M. D. Abel, and J. B. Seward, "Natriuretic peptide levels in atrial fibrillation: a prospective hormonal and Dopplerechocardiographic study," Journal of the American College of Cardiology, vol. 35, no. 5, pp. 1256-1262, 2000.

[62] G. Novo, D. Guttilla, G. Fazio, D. Cooper, and S. Novo, “The role of the renin-angiotensin system in atrial fibrillation and the therapeutic effects of ACE-Is and ARBS," British Journal of Clinical Pharmacology, vol. 66, no. 3, pp. 345-351, 2008.

[63] K. Karason, H. Molgaard, J. Wikstrand, and L. Sjostrom, "Heart rate variability in obesity and the effect of weight loss," The American Journal of Cardiology, vol. 83, no. 8, pp. 12421247, 1999.

[64] X. Jouven, M. Desnos, C. Guerot, and P. Ducimetiere, "Predicting sudden death in the population: the Paris Prospective Study I," Circulation, vol. 99, no. 15, pp. 1978-1983, 1999.

[65] E. D. Abel, S. E. Litwin, and G. Sweeney, "Cardiac remodeling in obesity," Physiological Reviews, vol. 88, no. 2, pp. 389-419, 2008.

[66] A. P. Lalani, B. Kanna, J. John, K. J. Ferrick, M. S. Huber, and L. E. Shapiro, "Abnormal signal-averaged electrocardiogram (SAECG) in obesity," Obesity Research, vol. 8, no. 1, pp. 2028, 2000.

[67] H. Huang, V. Amin, M. Gurin et al., "Diet-induced obesity causes long QT and reduces transcription of voltage-gated potassium channels," Journal of Molecular and Cellular Cardiology, vol. 59, pp. 151-158, 2013.

[68] B. H. McCully, W. Hasan, C. T. Streiff et al., "Sympathetic cardiac hyperinnervation and atrial autonomic imbalance in diet-induced obesity promote cardiac arrhythmias," American Journal of Physiology-Heart and Circulatory Physiology, vol. 305, no. 10, pp. H1530-H1537, 2013.
[69] K. Kalantar-Zadeh, G. Block, T. Horwich, and G. C. Fonarow, "Reverse epidemiology of conventional cardiovascular risk factors in patients with chronic heart failure," Journal of the American College of Cardiology, vol. 43, no. 8, pp. 14391444, 2004.

[70] A. Oreopoulos, R. Padwal, K. Kalantar-Zadeh, G. C. Fonarow, C. M. Norris, and F. A. McAlister, "Body mass index and mortality in heart failure: a meta-analysis," American Heart Journal, vol. 156, no. 1, pp. 13-22, 2008.

[71] A. Romero-Corral, V. M. Montori, V. K. Somers et al., "Association of bodyweight with total mortality and with cardiovascular events in coronary artery disease: a systematic review of cohort studies," The Lancet, vol. 368, no. 9536, pp. 666-678, 2006.

[72] R. H. Mehta, R. M. Califf, J. Garg et al., "The impact of anthropomorphic indices on clinical outcomes in patients with acute ST-elevation myocardial infarction," European Heart Journal, vol. 28, no. 4, pp. 415-424, 2007.

[73] A. O. Badheka, A. Rathod, M. A. Kizilbash et al., "Influence of obesity on outcomes in atrial fibrillation: yet another obesity paradox," The American Journal of Medicine, vol. 123, no. 7, pp. 646-651, 2010.

[74] J. Wang, Y. M. Yang, J. Zhu, H. Zhang, and X. H. Shao, “Obesity paradox in patients with atrial fibrillation and heart failure," International Journal of Cardiology, vol. 176, no. 3, pp. 1356-1358, 2014.

[75] A. Sharma, C. J. Lavie, J. S. Borer et al., "Meta-analysis of the relation of body mass index to all-cause and cardiovascular mortality and hospitalization in patients with chronic heart failure," The American Journal of Cardiology, vol. 115, no. 10, pp. 1428-1434, 2015.

[76] B. Zafrir, N. Salman, M. G. Crespo-Leiro et al., "Body surface area as a prognostic marker in chronic heart failure patients: results from the Heart Failure Registry of the Heart Failure Association of the European Society of Cardiology," European Journal of Heart Failure, vol. 18, no. 7, pp. 859-868, 2016.

[77] S. G. Ellis, J. Elliott, M. Horrigan, R. E. Raymond, and G. Howell, "Low-normal or excessive body mass index: newly identified and powerful risk factors for death and other complications with percutaneous coronary intervention," The American Journal of Cardiology, vol. 78, no. 6, pp. 642-646, 1996.

[78] H. S. Gurm, P. L. Whitlow, K. E. Kip, and BARI Investigators, "The impact of body mass index on short- and long-term outcomes inpatients undergoing coronary revascularization: insights from the bypass angioplasty revascularization investigation (BARI)," Journal of the American College of Cardiology, vol. 39, no. 5, pp. 834-840, 2002.

[79] C. E. Hastie, S. Padmanabhan, R. Slack et al., "Obesity paradox in a cohort of 4880 consecutive patients undergoing percutaneous coronary intervention," European Heart Journal, vol. 31, no. 2, pp. 222-226, 2010.

[80] A. Oreopoulos, F. A. McAlister, K. Kalantar-Zadeh et al., "The relationship between body mass index, treatment, and mortality in patients with established coronary artery disease: a report from APPROACH," European Heart Journal, vol. 30, no. 21, pp. 2584-2592, 2009.

[81] E. Nikolsky, E. Kosinski, G. J. Mishkel et al., "Impact of obesity on revascularization and restenosis rates after bare-metal and drug-eluting stent implantation (from the TAXUS-IV trial)," The American Journal of Cardiology, vol. 95, no. 6, pp. 709-715, 2005. 
[82] I. Akin, R. Tölg, M. Hochadel et al., "No evidence of "obesity paradox" after treatment with drug-eluting stents in a routine clinical practice: results from the prospective multicenter German DES.DE (German Drug-Eluting Stent) Registry," JACC: Cardiovascular Interventions, vol. 5, no. 2, pp. 162169, 2012.

[83] L. Gruberg, N. J. Weissman, R. Waksman et al., "The impact of obesity on the short-term and long-term outcomes after percutaneous coronary intervention: the obesity paradox?," Journal of the American College of Cardiology, vol. 39, no. 4, pp. 578-584, 2002.

[84] D. R. Holmes Jr, H. D. White, K. S. Pieper, S. G. Ellis, R. M. Califf, and E. J. Topol, "Effect of age on outcome with primary angioplasty versus thrombolysis," Journal of the American College of Cardiology, vol. 33, no. 2, pp. 412-419, 1999.

[85] E. E. Calle, M. J. Thun, J. M. Petrelli, C. Rodriguez, and C. W. Heath Jr, "Body-mass index and mortality in a prospective cohort of U.S. adults," New England Journal of Medicine, vol. 341, no. 15, pp. 1097-1105, 1999.

[86] C. J. Lavie and H. O. Ventura, "Weighing in on obesity and the obesity paradox in heart failure," Journal of Cardiac Failure, vol. 17, no. 5, pp. 381-383, 2011.

[87] C. Kistorp, J. Faber, S. Galatius et al., "Plasma adiponectin, body mass index, and mortality in patients with chronic heart failure," Circulation, vol. 112, no. 12, pp. 1756-1762, 2005.

[88] G. O'Donovan, A. Owen, E. M. Kearney et al., "Cardiovascular disease risk factors in habitual exercisers, lean sedentary men and abdominally obese sedentary men," International Journal of Obesity, vol. 29, no. 9, pp. 1063-1069, 2005.

[89] C. Goossens, M. B. Marques, S. Derde et al., "Premorbid obesity, but not nutrition, prevents critical illness-induced muscle wasting and weakness," Journal of Cachexia, Sarcopenia and Muscle, vol. 8, no. 1, pp. 89-101, 2017.

[90] M. De Rosa, J. Gambardella, J. Shu, and G. Santulli, “Dietary fat is a key determinant in balancing mitochondrial dynamics in heart failure: a novel mechanism underlying the obesity paradox," Cardiovascular Research, vol. 114, no. 7, pp. 925927, 2018.

[91] J. Gambardella, B. Trimarco, G. Iaccarino, and G. Santulli, "New insights in cardiac calcium handling and excitationcontraction coupling," Advances in Experimental Medicine and Biology, vol. 1067, pp. 373-385, 2018.

[92] Y. Guo, Z. Wang, X. Qin et al., "Enhancing fatty acid utilization ameliorates mitochondrial fragmentation and cardiac dysfunction via rebalancing optic atrophy 1 processing in the failing heart," Cardiovascular Research, vol. 114, no. 7, pp. 979-991, 2018.

[93] H. Schunkert, L. Harrell, and I. F. Palacios, "Implications of small reference vessel diameter in patients undergoing percutaneous coronary revascularization," Journal of the American College of Cardiology, vol. 34, no. 1, pp. 40-48, 1999.

[94] D. P. Foley, R. Melkert, and P. W. Serruys, "Influence of coronary vessel size on renarrowing process and late angiographic outcome after successful balloon angioplasty," Circulation, vol. 90, no. 3, pp. 1239-1251, 1994.

[95] B. D. Powell, R. J. Lennon, A. Lerman et al., "Association of body mass index with outcome after percutaneous coronary intervention," The American Journal of Cardiology, vol. 91, no. 4, pp. 472-476, 2003.

[96] P. Chase, R. Arena, J. Myers et al., "Relation of the prognostic value of ventilatory efficiency to body mass index in patients with heart failure," The American Journal of Cardiology, vol. 101, no. 3, pp. 348-352, 2008.

[97] E. G. Artero, D. C. Lee, C. J. Lavie et al., "Effects of muscular strength on cardiovascular risk factors and prognosis," Journal of Cardiopulmonary Rehabilitation and Prevention, vol. 32, no. 6, pp. 351-358, 2012.

[98] A. L. Clark, "Tipping the scales toward fitness as a key modifier of the obesity paradox in heart failure," European Journal of Heart Failure, vol. 18, no. 5, pp. 554-555, 2016.

[99] M. F. Piepoli, U. Corrà, F. Veglia et al., "Exercise tolerance can explain the obesity paradox in patients with systolic heart failure: data from the MECKI Score Research Group," European Journal of Heart Failure, vol. 18, no. 5, pp. 545-553, 2016.

[100] E. Zamora, J. Lupón, C. Enjuanes et al., "No benefit from the obesity paradox for diabetic patients with heart failure," European Journal of Heart Failure, vol. 18, no. 7, pp. 851858, 2016.

[101] M. F. Piepoli, "Obesity in heart failure: is it time to rethink the paradox?," European Journal of Heart Failure, vol. 19, no. 12, p. 1736, 2017.

[102] C. Cuspidi, M. Rescaldani, C. Sala, and G. Grassi, "Leftventricular hypertrophy and obesity: a systematic review and meta-analysis of echocardiographic studies," Journal of Hypertension, vol. 32, no. 1, pp. 16-25, 2014.

[103] I. E. G. M. Rocha, E. G. Victor, M. C. Braga, O. B. e. Silva, and M. d. M. C. Becker, "Echocardiography evaluation for asymptomatic patients with severe obesity," Arquivos Brasileiros de Cardiologia, vol. 88, no. 1, pp. 52-58, 2007.

[104] S. F. Nagueh, C. P. Appleton, T. C. Gillebert et al., "Recommendations for the evaluation of left ventricular diastolic function by echocardiography," Journal of the American Society of Echocardiography, vol. 22, no. 2, pp. 107-133, 2009.

[105] V. Di Bello, I. Fabiani, L. Conte et al., "New echocardiographic techniques in the evaluation of left ventricular function in obesity," Obesity (Silver Spring), vol. 21, no. 5, pp. 881-892, 2013.

[106] M. Murat Tumuklu, I. Etikan, B. Kisacik, and M. Kayikcioglu, "Effect of obesity on left ventricular structure and myocardial systolic function: assessment by tissue Doppler imaging and strain/strain rate imaging," Echocardiography, vol. 24, no. 8, pp. 802-809, 2007.

[107] M. R. Holland, K. D. Wallace, and J. G. Miller, "Potential relationships among myocardial stiffness, the measured level of myocardial backscatter ("image brightness"), and the magnitude of the systematic variation of backscatter (cyclic variation) over the heart cycle," Journal of the American Society of Echocardiography, vol. 17, no. 11, pp. 1131-1137, 2004.

[108] S. A. Wickline, L. J. Thomas 3rd, J. G. Miller, B. E. Sobel, and J. E. Perez, "A relationship between ultrasonic integrated backscatter and myocardial contractile function," Journal of Clinical Investigation, vol. 76, no. 6, pp. 2151-2160, 1985.

[109] T. Edvardsen, B. L. Gerber, Ĵ. Garot, D. A. Bluemke, J. A. C. Lima, and O. A. Smiseth, "Quantitative assessment of intrinsic regional myocardial deformation by Doppler strain rate echocardiography in humans: validation against threedimensional tagged magnetic resonance imaging," Circulation, vol. 106, no. 1, pp. 50-56, 2002.

[110] R. M. Lang, L. P. Badano, W. Tsang et al., "EAE/ASE recommendations for image acquisition and display using three- 
dimensional echocardiography," Journal of the American Society of Echocardiography, vol. 25, no. 1, pp. 3-46, 2012.

[111] A. el-Gamal, D. Gallagher, A. Nawras et al., "Effects of obesity on QT, RR, and QTc intervals," The American Journal of Cardiology, vol. 75, no. 14, pp. 956-959, 1995.

[112] M. E. Mshui, T. Saikawa, K. Ito, M. Hara, and T. Sakata, "QT interval and QT dispersion before and after diet therapy in patients with simple obesity," Proceedings of the Society for Experimental Biology and Medicine, vol. 220, no. 3, pp. 133-138, 1999.

[113] A. Lubinski, Z. Kornacewicz-Jach, A. M. Wnuk-Wojnar et al., "The terminal portion of the $\mathrm{T}$ wave: a new electrocardiographic marker of risk of ventricular arrhythmias," Pacing and Clinical Electrophysiology, vol. 23, no. 11P2, pp. 1957$1959,2000$.

[114] M. Shimizu, H. Ino, K. Okeie et al., "T-peak to T-end interval may be a better predictor of high-risk patients with hypertrophic cardiomyopathy associated with a cardiac troponin I mutation than QT dispersion," Clinical Cardiology, vol. 25, no. 7, pp. 335-339, 2002.

[115] M. Yamaguchi, M. Shimizu, H. Ino et al., "T wave peak-toend interval and QT dispersion in acquired long QT syndrome: a new index for arrhythmogenicity," Clinical Science, vol. 105, no. 6, pp. 671-676, 2003.

[116] A. Braschi, M. G. Abrignani, V. C. Francavilla, and G. Francavilla, "Novel Electrocardiographic Parameters of Altered Repolarization in Uncomplicated Overweight and Obesity," Obesity, vol. 19, no. 4, pp. 875-881, 2010. 


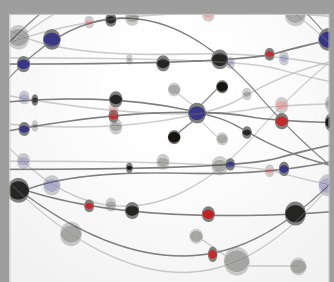

The Scientific World Journal
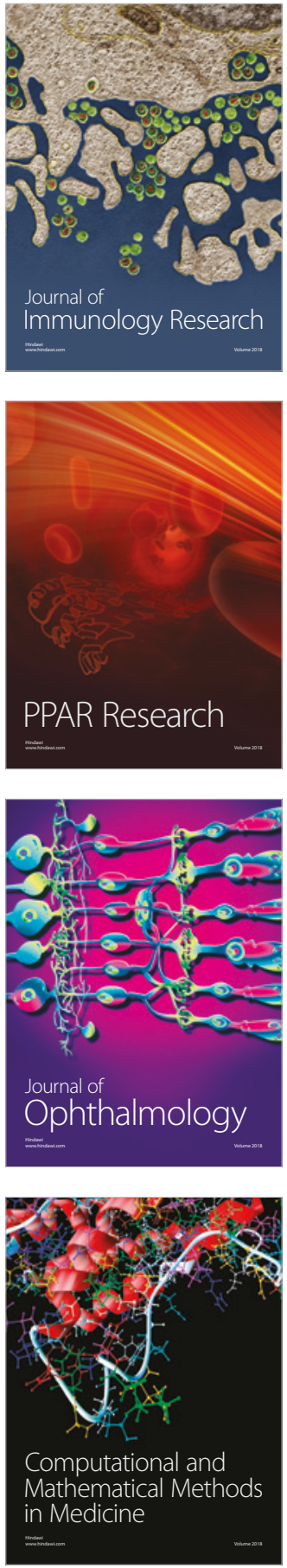

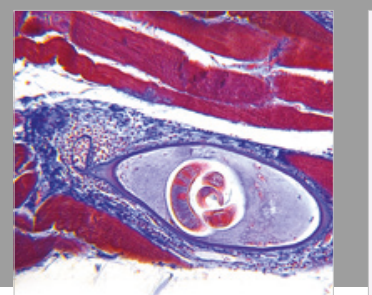

Gastroenterology Research and Practice

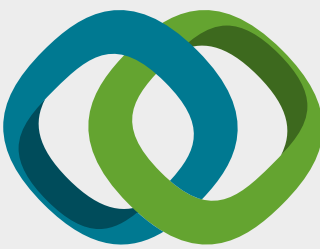

\section{Hindawi}

Submit your manuscripts at

www.hindawi.com
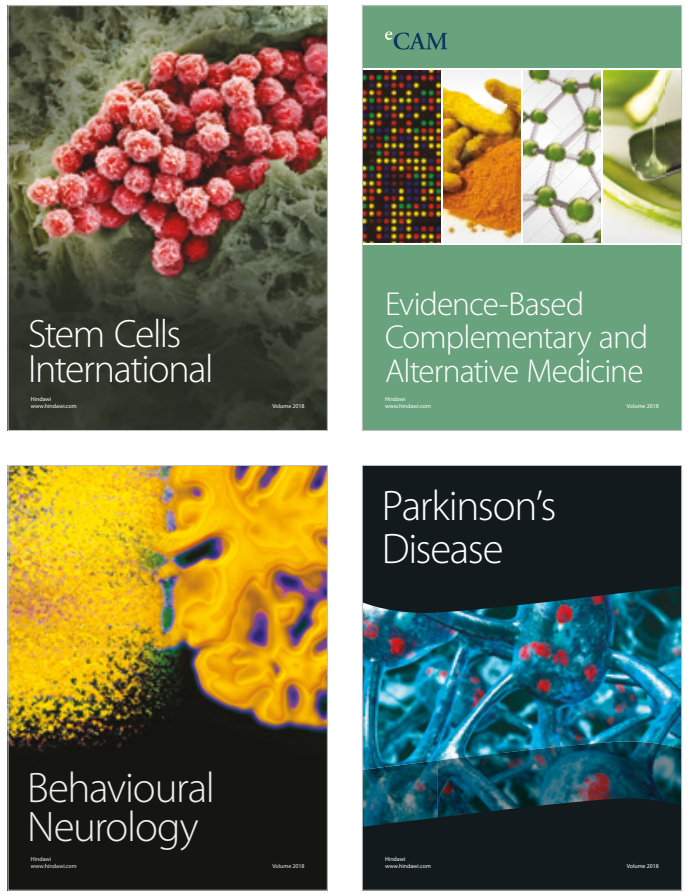

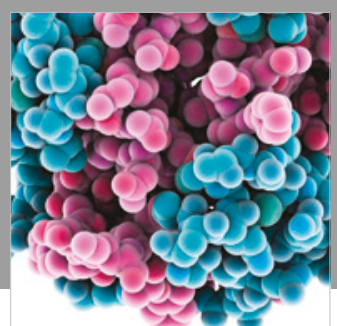

ournal of

Diabetes Research

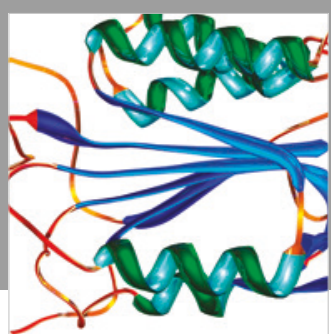

Disease Markers
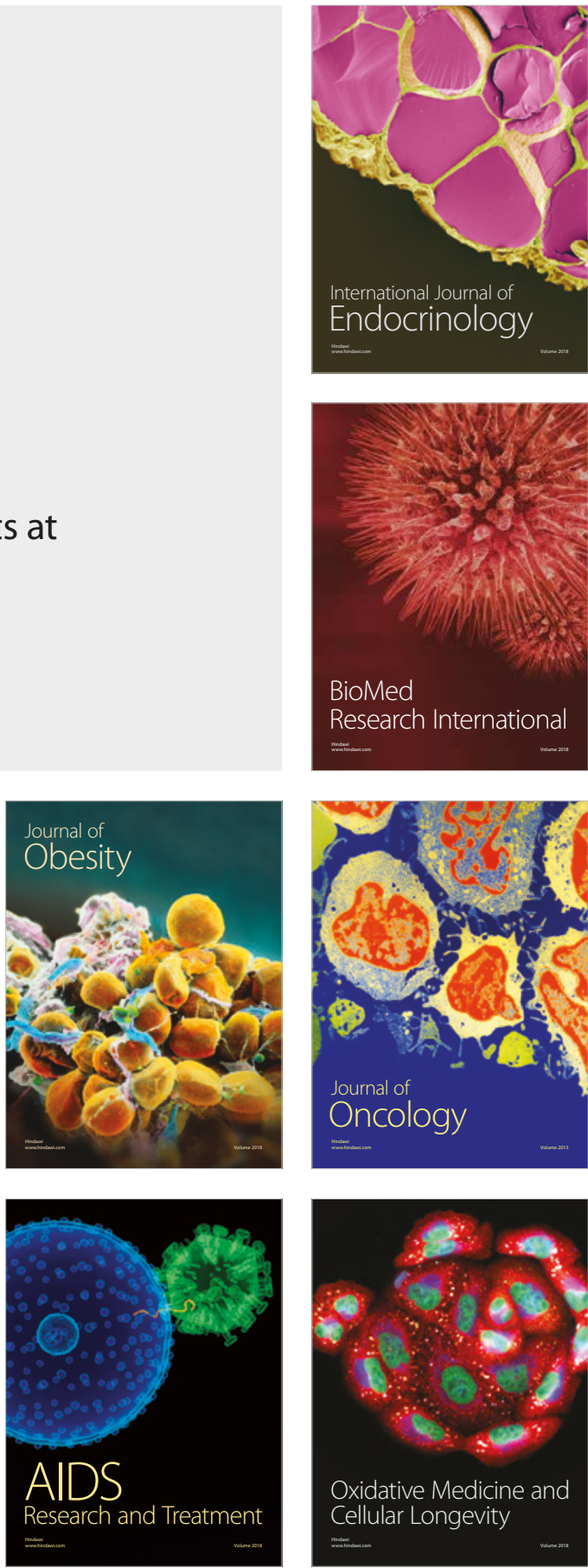